\title{
New law does little to ease research pain in Spain
}

\section{Validation of foreign degrees is still mired in expensive, time-consuming bureaucracy.}

Sir - We read with interest your editorial "Ending the pain in Spain" (Nature 428, 1; 2004) but feel that it did not adequately address the bureaucratic difficulties facing foreign-educated scientists when applying for jobs in Spain.

Applicants for government-funded permanent positions must provide either a Spanish doctorate or the Spanish ('homologated') equivalent of a foreign doctorate. This homologation procedure is expensive (several hundred euros for taxes, translation and other fees), involves excessive paperwork, and is timeconsuming, taking six months in theory but many years in practice.
The Spanish Ministry of Education passed a law on 20 February to address this issue, but the law does not provide much relief. Careful reading reveals few significant changes from the previous law.

Diplomas from foreign universities may now be validated in general, rather than for each individual case. This is a small step in the right direction, but if Spain is serious about improving the mobility of researchers, it should consider following EU directive 89/48/CEE and scrap the homologation requirement entirely. Failing that, it should remove the requirement to homologate the undergraduate degree, which requires the same paperwork and processing times, and consider accepting documents in English, as many European universities already do.

We have sent an open letter to the Spanish ministers of education and of science, asking them to consider removing these remaining barriers both to Spanish scientists who wish to return home and to any scientist with the required expertise and will to come and work in Spain.

Mark van Raaij ${ }^{*}$

Departamento de Bioquímica, Facultad de Farmacia, Universidad de Santiago,

15782 Santiago de Compostela, Spain

${ }^{*}$ Signed on behalf of the Asociación Nacional de Investigadores Ramón y Cajal and 89 international co-authors, whose names and contact details are available directly from the author.

\section{Spain: politicians need to challenge the status quo}

Sir - As a Spanish postdoc working outside Spain for almost five years, I welcome your Editorial "Ending the pain in Spain" (Nature 428, 1; 2004).

As you say, science rarely occupies the headlines in the Spanish press. When it does, the story is often a comment on the achievements of Spanish researchers working abroad. As things improve, more scientists will return to Spain, but not as quickly as you suggest.

For example, it is not true that "Over the past three years, [the Ramón y Cajal programme] has repatriated almost 2,000 of Spain's diaspora of postdocs". If you look more carefully at the numbers, you will see that most of the 1,944 positions offered went to Spanish scientists already living in Spain, whereas only $21.4 \%$ were awarded to Spanish researchers living abroad. To be fair, the programme was not aimed solely at repatriating Spanish researchers, but intended to increase the overall number of researchers working in Spain by providing steady five-year contracts to both Spanish and non-Spanish nationals.

There are several reasons why few Spaniards working abroad have been attracted to this scheme. One of these is that their own research initiatives will often be subordinated to that of the group that receives them. This is understandable, to some extent, because this group will pay part of their salaries and provide them with space and equipment. Another is the uncertain future of people holding such positions. Contrary to the suggestion in your Editorial, the competition for funds in Spain could hardly be stiffer. Numerous people have returned to Spain, attracted by schemes operating before the Ramón y Cajal programme, and were then abandoned by the system. Many of these had to emigrate again. This situation will continue until our politicians show an interest in challenging the status quo.

Miguel Ortiz Lombardía

York Structural Biology Laboratory,

University of York, Heslington,

York YO10 5YW, UK

\section{Fusion: Bush agrees it's time to end the impasse}

Sir - I am puzzled by your Editorial "Time for Japan to shine?" (Nature 427, 763 ; 2004) on resolving the stalemate over the choice of a site for the fusion project ITER. You analyse the situation with the Japanese and European bids fairly and accurately. You conclude that if one or the other is technically superior, the facility should be sited there, but that in the event of a tie or a near tie, then Japan should be the chosen site.

I agree with your analysis and have been saying the same thing for some time.

My puzzlement comes from the last paragraph in which you say "Europe should turn the other cheek to the Bush administration's mischief-making and break the impasse". This position, although new to Nature, is one that the United States government has long held.

I would have expected Nature to reserve its regrettable sarcasm for situations in which you and the Bush administration disagreed.

\section{Burton Richter}

Stanford University, SLAC MS-80, 2575 Sand Hill Road, Menlo Park,

California 94025, USA

\section{Fusion: choose Japan for international balance}

Sir - Your Editorial "Time for Japan to shine?" (Nature 427, 763; 2004) offered the world a way out of the present stalemate concerning the selection of a site for the fusion project ITER.

In contrast, the correspondence by P. Vandenplas (Nature 428, 119; 2004) seems counter-productive. By staking Europe's claim to an "uncontested leading role in fusion", Vandenplas missed the main point. As your Editorial correctly notes, Japan genuinely yearns for an international project of the size of ITER.

If we look beyond fusion and see the broader context of international science, we can see the need for international balance in large science facilities. Technical experts from each of the ITER parties have already certified both Cadarache and Rokkasho to be acceptable sites for ITER. However, when viewed from the level of international policy-making, it is clear that choosing the Rokkasho site will bring Japan into the international community of science leaders.

I applaud the wisdom of your Editorial and its broad view of international science. This opportune moment in fusion's history may not last long. Fusion scientists everywhere must agree with your impatient plea, "The time has come to choose a site." For this to happen, we must certainly look beyond our local concerns and work to find the larger political solution that embraces the scientific aspirations of all nations.

Michael E. Mauel

Department of Applied Physics and Applied Mathematics, Columbia University, 500 W. 120th

Street, New York, New York 10027, USA 